\title{
Asymmetric pathogen spillover favors exotic plants over natives
}

\author{
Lauren Waller ${ }^{1}$, Warwick Allen ${ }^{2}$, Amanda Black ${ }^{1}$, Jonathan Tonkin ${ }^{2}$, Jason Tylianakis ${ }^{2}$, \\ Angela Wakelin ${ }^{1}$, and Ian Dickie ${ }^{2}$ \\ ${ }^{1}$ Lincoln University \\ ${ }^{2}$ University of Canterbury
}

May 10, 2021

\begin{abstract}
Exotic plants can escape from specialist pathogenic microorganisms in their new range, but may simultaneously accumulate generalist pathogens. This creates the potential for pathogen spillover, which could alter plant-competitive hierarchies via apparent competition. To assess the potential for and consequences of pathogen spillover in invaded communities, we conducted a community-level plant-soil feedback experiment in experimental communities that ranged in the extent of exotic dominance, using next-generation sequencing to characterize sharing of putatively-pathogenic, root-associated fungi (hereafter, 'pathogens'). Exotic plants outperformed natives in communities, despite being subject to stronger negative plant-soil feedbacks in monoculture and harboring higher relative abundance of pathogens. Exotic plants made more general associations with pathogens, making them more prone to sharing pathogens with natives and exerting apparent competition. These data suggest that exotic plants accumulate generalist pathogens that are shared with native plants, conferring an indirect benefit to exotic, over native plants.
\end{abstract}

\section{INTRODUCTION}

Pathogenic microorganisms have considerable influence over species distributions (Dinoor \& Eshed 1984; Bever 2015). Pathogens can disrupt plant communities by reducing the abundance of susceptible hosts, thereby benefitting those that are less susceptible in the community (Power \& Mitchell 2004; Mordecai 2011). In invaded communities, exotic plant species can benefit when they support and tolerate a high abundance of generalist pathogens that are shared with native species (i.e. Accumulation of Local Pathogens Hypothesis, Eppinga 2006; Boreret al. 2007; Mitchell et al. 2010), resulting in pathogen-mediated apparent competition between plants (Holt 1977; Holt 2017, also known as disease-mediated invasion, Strauss et al.2012). Yet, the relative importance of pathogen accumulation in invaded communities and the means of pathogen spread via exotic hosts are difficult to quantify experimentally, and mark an important gap in our knowledge of plant community dynamics (Goss et al. 2020).

Plant hosts vary widely in their capacity to amplify and transmit pathogens (Paull et al. 2012). Asymptomatic or mildly symptomatic 'amplification hosts' (also known as reservoir hosts) can significantly disrupt natural communities by transmitting disease (Cronin et al. 2010). Several successful exotic plant hosts are known to accumulate pathogens that spill over onto native plants and suppress their growth (Malmstrom et al. 2005; Strauss et al. 2012), but the generality of this phenomenon is unknown. By contrast, exotic plants can have a neutral effect on pathogen abundance, or decrease it via the dilution effect (i.e. lower proportion of suitable hosts in the community, Ostfeld \& Keesing 2000; Keesing, Holt \& Ostfeld 2006) if they escape pathogens (i.e. Enemy Release Hypothesis, Keane \& Crawley 2002) or are suppressed more than native plants (Stricker et al.2016). Understanding whether exotic plants amplify or dilute generalist pathogens in a community is key to understanding whether or not disease-mediated invasion may occur.

Exotic plants are likely to act as amplification hosts for several reasons. First, many exotic plants have 
"quick-return" strategies (i.e. faster growth, high nitrogen in tissues, Leishman et al.2007; van Kleunen et al. 2010) and are more competent hosts for antagonists, including pathogens, than "slow-return" species (Strauss \& Agrawal 1999; Cronin et al. 2010; Cappelli et al. 2020; Allen et al. 2021). Second, many invasive plants tolerate damage from enemies with minimal impact on plant fitness (Roy \& Kirchner 2000; Ashton \& Lerdau 2008; Goss et al. 2020), and/or can replace tissues lost to enemies faster than slow-growing species (Gianoli \& Salgado-Luarte 2017; Allen et al. 2021). Third, exotic plants can occur at high abundance locally, increasing pathogen establishment and spread opportunities (Burdon \& Chilvers 1982; Gilbert 2002). Thus, maximum transmission rates by pathogens may occur in communities where the majority of biomass is made up of tolerant, exotic hosts (Parker \& Gilbert 2004). Because many exotic, invasive plants possess quick-return strategies, are disease-tolerant, and occur at high abundance, they likely meet these criteria to act as amplification hosts.

Identifying amplification hosts in a multi-host, multi-pathogen system has proven challenging (Paull et al. 2012). Despite evidence that many plant pathogens are generalists and infect multiple hosts in the community (Parker and Gilbert 2007), interactions between plants and pathogens are typically studied in isolation of the wider community (but see Hawksworth 2001). Studies that do take a microbial community approach often use plant-soil feedbacks (Bever et al. 1997), comparing how plants differ in their influence on and response to pathogen communities in soils. However, plant-soil feedback experiments rarely use more than 1-2 plant hosts or characterize specific microbial functional groups, thereby failing to address whether effects of soil biota are due to pathogens or parasitic mutualists (e.g. mycorrhizal fungi, Klironomos 2003). Further, these tests cannot distinguish between the Enemy Release vs. Accumulation of Local Pathogens Hypotheses, because the absence of a growth depression from antagonistic soil biotic communities could mean that plants have either escaped or are simply tolerating accumulated pathogens. Finally, it is unclear whether plant-soil feedback effects observed in monoculture translate to a community, where sharing of interaction partners may produce influential indirect interactions (Allen 2020).

To test whether exotic plants accumulate generalist pathogens that spill over on to native plants, we characterized fungal pathogen communities in the roots of native and exotic plants growing together in 8-species communities $(\mathrm{n}=80)$ ranging in exotic dominance from $0-100 \%$. We focus on soil-borne fungi, as these are the most common and aggressive pathogen group affecting plants (Delgado-Baquerizo et al. 2020). We quantified the degree of sharing between native and exotic plant hosts by calculating the proportion of OTUs shared, the generality of associations of both plants and fungi (relative to other species in the community), and the frequency at which generalists are shared with other plants. We also conducted a single-species plant-soil feedback experiment with the plant species and compared their responses to those in the community-level experiment, where we also included a plant-soil feedback treatment. We addressed the following research questions: 1) Do exotic plants accumulate generalist fungal taxa that are known to cause plant disease (i.e. putative pathogens)? 2) Given their higher generalism, do exotic plants share a greater proportion of fungal pathogens with natives than do other native plants? 3) Does feedback between exotic plants and putatively pathogenic fungal taxa explain exotic plant success alone and in plant communities? And 4) Do plant-soil feedbacks in monoculture predict feedbacks in a community? Our results show that exotic plants are more generalist in their associations compared with natives, driving asymmetric spillover of pathogens from exotic to native plants compared to null expectation, which correlates with exotic plant success in communities but not monoculture.

\section{MATERIALS AND METHODS}

\section{Study site and experimental design}

We initiated this study in 2016, in a glasshouse and in large mesocosm pots set in a fallow field on the Lincoln University campus (Lincoln, New Zealand. $43.6434^{\circ} \mathrm{S}, 172.4678^{\circ} \mathrm{E}$, elevation $10 \mathrm{~m}$ ), and completed it in 2019 (Waller et al.2020). We designed 20 communities, each containing eight unique plant species taken from a pool of 39 species (species details listed in Table S1), and grown in $125 \mathrm{~L}$ pots (575 mm dia.). Full methods are described in Waller et al. (2020), but briefly summarized here. Communities varied orthogonally in their proportion of exotic plant species $(0,25,50,75,100 \%)$ and woody plant species $(0,25,38,63 \%)$. Each of 
the 20 plant communities was replicated four times ( 80 pots total) and received one of two soil treatments, described below. We included an additional 80 pots with a treatment with addition of herbivores (reported in Walleret al. 2020 and Allen et al. 2021). However, that treatment was not relevant for our hypotheses, so is excluded from the current analysis.

\section{Plant-soil feedback}

To test whether plant-soil feedbacks in monoculture can predict feedbacks in a community (Question 4), we performed a monoculture and a community-level plant-soil feedback experiment using a common, fieldcollected soil inoculum cultured by each of our plant species. To culture the live inoculum, we collected approximately $1 \mathrm{~m}^{3}$ of topsoil from each of eight sites across Canterbury, New Zealand in June 2016. We grew each of our 39 focal plant species (Table S1) in a $10 \mathrm{~L}$ pot (12-20 replicates per species) containing the live soil mixed in a 1:2 ratio with a pasteurized background media (50:50 mineral soil:sand that had been steamed twice for 60 minutes at $100^{\circ} \mathrm{C}$ internal temperature). After approximately 9-10 months of growth, we harvested and discarded aboveground material from each pot, but retained and chopped the roots finely and reincorporated them into the soil. After combining replicates of each species, we had soils from each of the 39 species that could be used as "home" (i.e. cultured by a conspecific) or "away" (i.e. cultured by a heterospecific) soil in the monoculture and community-level experiments.

To establish the monoculture plant-soil feedback experiment, we grew twenty individuals of each of the 39 plant species in $10 \mathrm{~L}$ pots containing $7 \mathrm{~L}$ of freshly pasteurized soil:sand mixture (described above), with ten individuals receiving $2.5 \mathrm{~L}$ of "home" soil and the other ten receiving $2.5 \mathrm{~L}$ of "away" soil (one of ten different randomly chosen heterospecific species). After approximately 10 months of growth, we harvested all above and belowground plant material and determined the dry weight of all individuals.

To establish the community-level plant-soil feedback experiment, we grew each 8-species community in pots containing a bottom layer of $22 \mathrm{~L}$ of gravel, covered with $88 \mathrm{~L}$ of pasteurized soil:sand mixture and topped with $12 \mathrm{~L}$ of the live inoculum soil. To prepare the "home" soils, we mixed soil from each of the resident species in that community in equal parts. "Away" soils were mixtures of eight species occurring in one of the other 19 plant communities (a different community where none of the residents occurred). After approximately one year of growth, we recorded the realized richness of each mesocosm community, harvested all above and belowground plant material, and determined dry weight of all individuals. Root samples from each individual plant were retained, washed and frozen immediately at $-80{ }^{\circ} \mathrm{C}$ for subsequent molecular analysis.

\section{Molecular sequencing and bioinformatics}

DNA was extracted from a total of 491 roots harvested from individual plants from all 80 mesocosms at the end of the experiment, using MoBio PowerSoil extraction kits. We characterized the fungal communities by amplifying the internal transcribed spacer (ITS) of the ribosomal RNA (rRNA) operon using polymerase chain reaction (PCR) with the barcoded primers fITS7/ITS4 (Ihrmark et al. 2012) (PCR conditions are described in Waller et al. 2020). Amplicons were sequenced on an Illumina MiSeq analyzer using the 600cycle Reagent Kit V3, delivering 2 X 300 base pair reads/sequence.

Sequences were paired, putative chimeras removed, and clustered into operational taxonomic units (OTUs) at $97 \%$ sequence similarity using Vsearch (Rognes et al. 2016). Quality and barcode filtering resulted in $6,093,371$ reads with a median length of 225 bases.

We assigned functional attributes to OTUs using FUNGuild (Nguyenet al. 2016) and retained only the taxa assigned as "probable" or "highly probable" plant pathogens for subsequent analyses (details about taxa from FUNGuild are listed in Table S2). We restricted our inclusion of taxa to those that receive the majority of their nutrients by harming host cells (defined as "pathotrophs" by FUNGuild), and excluded taxa with mixed strategies from our analyses (i.e. "pathotroph-saprotroph"), as many of these taxa receive most of their nutrients by breaking down dead host cells. We acknowledge that by limiting our pathogen assignment in this way we have likely excluded many taxa that may be pathogens in some environments, so our results represent a conservative analysis of the pathogen communities hosted by our plants. Moreover, the taxa listed 
here are putative pathogens (herein referred to simply as "pathogens"), as we rely on commonly accepted life history descriptions rather than performing real-time functional assays on each taxon.

\section{Fatty acid extraction and quantification}

As an independent measure of fungal biomass, we quantified phospholipid fatty acids (PLFA) from approximately $10 \mathrm{~g}$ of freeze-dried soil from each mesocosm pot. Briefly, lipids were extracted by a commercial laboratory (Microbial ID, Newark, DE, USA), using methods described in Frostegård et al . (2011) and Wal-

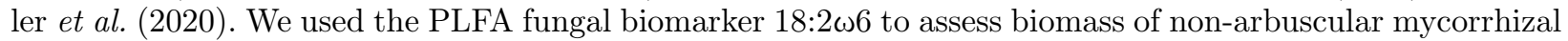
fungi.

\section{Data analysis}

We used generalized linear mixed-effects models (GLMMs, with the package lme4, version 1.1-23 (Bates et al. 2014)) in R, version 3.2.3 (R Core Team 2019) for all models, unless specified otherwise (see Table 1 for final models). We used the emmeans package (Lenth 2020) in $\mathrm{R}$ to calculate estimated marginal means and conduct post-hoc tests. Chi-square tests and p-values were calculated using the Anova function in the package car (Fox \& Weisberg 2019).

We calculated species richness (i.e. alpha-diversity) of fungal pathogens in plant roots and plant communities. First, total fungal richness was calculated as the sum of OTUs present in a taxa/sample matrix of all fungi that was rarefied to the minimum size per sample (1,500 sequences). Rarefaction ensures that all samples can be compared at the same sequencing depth, but did result in the loss of 15 individual plants (out of 490) from the dataset (those which had $<1,500$ sequences). Pathogen richness was calculated by subsetting the rarefied fungal taxa/sample matrix to include only the taxa identified by FUNGuild as pathogenic to plants. To calculate pathogen relative abundance in plant roots, we summed the total number of fungal pathogen sequences found in each individual plants' roots and divided that by the total number of fungal sequences in that root. To calculate pathogen relative abundance at the community level, we took the ratio of the sum of the total number of fungal pathogen sequences and the sum of all fungal sequences found in the roots in each community.

To study partner sharing, we calculated the species-level interaction network metrics normalized degree and closeness centrality (weighted closeness) using the $\mathrm{R}$ package bipartite (Dormann et al. 2011). Normalized degree measures the proportion of all possible partners in the community that an organism interacts with, which we used as an indicator of generality. Normalized degree was calculated for each 1) plant and 2) pathogen inhabiting the plant roots. Closeness centrality measures the degree to which a plant species mediates sharing/indirect interactions among the community. It was calculated on a unipartite (plant only) projection of the bipartite (plant-fungal) network, whereby plant species are connected if they share a fungal partner. High closeness centrality indicates that a plant species has a short path to any other plant species in the unipartite network, such that it tends to share partners with many species or with particular species that share with many others. Given this sharing, we used closeness here as an indicator of how much influence a plant could have in a community in terms of its ability to indirectly affect other species by spreading pathogens; a negative equivalent to previous findings that closeness confers indirect benfits in belowground mutualisms (Tylianakis et al. 2018). Normalized degree of plants was modeled using a normal error distribution, pathogen relative abundance with a binomial distribution and normalized degree of pathogens and closeness centrality with a Gamma distribution. We used the logit link function in the binomial models and the log link function in all other models.

To test whether exotic plants accumulate fungal taxa that are known to cause plant disease (Question 1), we quantified how pathogen richness and relative abundance changed as a function of the proportion of exotics planted into the community (ranging from 0-100\%), our soil treatment (home or away) and their interaction as fixed effects. To account for non-independence of plants in the same mesocosm community, we added mesocosm (pot 1-80) nested in plant community (community 1-20) in the models as random effects. To test how the generality of interactions and the potential for interactions to be shared changed along the exotic plant gradient (Questions $1 \& 2$ ), we modeled normalized degree and closeness centrality (respectively) as a 
function of the same predictors described above. As an additional check, we ran all models again, replacing the proportion of exotics planted with the proportion realized at the end of the experiment to be sure both model results corroborated. We did this for each model that tested the effects of the proportion of exotics planted, and results were consistent between these two approaches (Table S2).

To understand differences in the way native vs. exotic plants interact with pathogens, independently of the extent of invasion, we ran a separate analysis focusing on only the 40 plant communities containing $100 \%$ natives or $100 \%$ exotic plants. We tested how pathogen richness and relative abundance, the generality of interactions (i.e. normalized degree) and the relative efficiency with which plants could potentially spread pathogens (i.e. closeness centrality) varied as a function of plant provenance, our soil treatment and their interaction as fixed effects. We added mesocosm nested in plant community and plant species as random effects in these models.

To test whether natives vs. exotics differ in the proportion of fungal pathogens they share (Question 2), we modeled pathogen sharing between native and exotic plants in each mesocosm community as a function of the proportion of exotics planted, the soil treatment and their interaction, with random factors as described above (and in Table 1). We excluded communities containing both $100 \%$ native and $100 \%$ exotic plants from this analysis (i.e. retained communities with 25,50 and $75 \%$ exotic) because there could be no sharing in those communities. To calculate the proportion of pathogens that were shared (or not) between native and exotic plants in a community, we calculated the number of pathogenic fungal taxa that were identified from 1) only native plant roots, 2) only exotic plant roots, or 3) both native and exotic plant roots in each mesocosm pot. We then calculated the proportion of pathogenic fungal taxa that were shared (between natives and exotics) in a mesocosm by dividing the number of shared pathogen OTUs by the total pathogen OTU richness in each mesocosm.

To determine whether exotics shared pathogens with natives more than would be expected by chance in each community, we simulated a null model showing how much sharing (as calculated above) we would expect along the full realized exotic gradient (i.e. proportion of exotic plants at the end of the experiment) if native and exotic plants were equivalent in their potential to share pathogens. We ran that model 1,000 times, randomizing the provenance of plants and randomly shuffling pathogen reads across plant individuals, to calculate a distribution of expected sharing. We then used a Monte Carlo simulation to compare that null model data to our observed molecular data of shared pathogens along the realized exotic gradient (more details about the null model can be found in Supplementary methods). We used polynomial regression and fitted a curvilinear line to model the relationship between sharing and exotic dominance and modeled the deviation in sharing from the mean of the null expectation along the realized exotic gradient for each mesocosm.

To test whether pathogen sharing between native and exotic plants correlates with exotic plant impact (Question 3), we calculated the relative interaction intensity index (RII, Armas, et al. 2004) for native and exotic plants and quantified its relationship with the proportion of pathogens shared between native and exotic plants in the community. The relative interaction intensity index quantifies the relative change in plant biomass from what was initially planted to what was realized at the end of the experiment, using the formula ((realized proportional biomass-planted proportional biomass)/(realized proportional biomass + planted proportional biomass)). We used this formula to measure changes in total native and total exotic biomass separately in each mesocosm. RII is bounded by 1 and -1 , so it controls for extreme values, with values above zero reflecting realized proportional growth that was higher than what was originally planted and values below zero reflecting realized proportional growth that was lower than what was originally planted.

To test whether plant-soil feedbacks in monoculture predict feedbacks in a community (Question 4), we evaluated whether plant-soil feedbacks (i.e. the difference between biomass of a given species in home vs. away soils) differed between native vs. exotic plants (i.e. interaction effect between soil treatment and plant provenance) and whether this difference was influenced by whether a plant was grown in monoculture or a community. To test this, we modeled 1) plant biomass from the monoculture experiment as a function of plant provenance, the soil treatment and their interaction as fixed effects with plant species as a random effect 
and 2) plant biomass from the communities as a function of plant provenance, the soil treatment and their interaction as fixed effects with plant species and mesocosm nested in plant community as random effects. While others have presented response ratios to evaluate plant-soil feedbacks (Brinkman et al. 2010), we were unable to calculate a response ratio in communities due to differential plant mortality across treatments.

\section{RESULTS}

From the 5,482 OTUs classified to be fungal, 3,851 were assigned functional attributes in FUNGuild. Of these, $9 \%$ (364 OTUs) were identified as being probable or highly probable pathogens of plants (other guild assignments can be found in Table S1).

Exotic plants accumulate generalist fungal taxa that are known to cause plant disease

Fungal pathogen richness did not differ between native and exotic plants, with individual plants hosting approximately 8 OTUs $\left( \pm 0.4\right.$ s.e., $\left.\chi^{2}=0.84, p>0.36\right)$ identified as pathogenic on average. Fungal pathogen richness did not change with the proportion of exotic plants planted in the community or differ in home vs. away soil (proportion of exotics: $\chi^{2}=1.05, \mathrm{p}=0.30$; soil treatment: $\chi^{2}=2.67, \mathrm{p}=0.10$, Table 1 ). Fungal pathogen relative abundance did not differ between native and exotic plants at the individual plant level $\left(\chi^{2}=1.31, \mathrm{p}=0.25\right.$, Table 1$)$, but pathogen relative abundance in communities increased along the exotic plant gradient $\left(\chi^{2}=5.17, p<0.02\right.$, Table 1, Fig. 1A). The soil treatment had no effect on pathogen abundance in communities $\left(\chi^{2}=0.27, \mathrm{p}=0.60\right)$ and no interaction with the proportion of exotics $\left(\chi^{2}=3.31, \mathrm{p}=0.07\right.$, Table 1 ). This gain in pathogen relative abundance along the exotic gradient was not simply due to reductions in other fungi, as total fungal biomass (using phospholipid fatty acid [PLFA] biomarkers) did not change along the exotic plant gradient $\left(\chi^{2}=0.16, \mathrm{p}=0.69\right.$, Table 1$)$.

On average, plants interacted with an increasing proportion of available pathogens along the exotic plant gradient, as indicated by plant-normalized degree $\left(\chi^{2}=37.97, \mathrm{p}<0.001\right.$, Table 1 , Fig. 1B). Likewise, more generalist pathogens inhabited the roots of plants in exotic-, compared with native-dominated communities, as indicated by the normalized degree of fungal pathogens $\left(\chi^{2}=45.12, \mathrm{p}<0.001\right.$, Table 1 , Fig. 1C).

When growing in $100 \%$ native or $100 \%$ exotic mesocosms, exotic plants were more generalist than native plants in their interactions with pathogens, as indicated by normalized degree $\left(\chi^{2}=21.80, p<0.001\right.$, Table 1 , Fig. 2A). Further, exotic plants were more central in the network, as indicated by mean closeness centrality values for natives vs. exotics $\left(\chi^{2}=36.57, \mathrm{p}<0.001\right.$, Table 1 , Fig. $\left.2 \mathrm{~B}\right)$, suggesting that exotic plants had a greater ability to indirectly affect others in the community by spreading pathogens, compared with native plants.

\section{Exotic plants share putative fungal pathogens with natives}

We found asymmetric sharing of pathogens between native and exotic plants along the exotic gradient (Fig. 3). The relationship between shared pathogens and exotic dominance in mixed communities (Fig. 3A) deviated significantly from null expectations (Fig. 3B). Exotic plants shared a greater proportion of pathogen OTUs than would be expected by chance, compared with native plants, which shared fewer pathogen OTUs than our null model predicted (Fig. 3) Plants shared $4 \%$ more pathogens in home compared with away soils $\left(\chi^{2}=6.37, \mathrm{p}=0.01\right.$, Table 1$)$. The observed proportion of shared pathogens appeared to reach a peak when the community contained approximately $60 \%$ exotic plants, while it was lowest in communities with $25 \%$ exotic plants (when both native and exotic plants were present; Fig. 3). Further, the efficiency at which plants shared pathogens with other plants increased with the proportion of exotic plants in the community, as indicated by increasing values of closeness centrality with increasing exotic dominance $\left(\chi^{2}=15.68, p<0.001\right.$, Table 1, Fig. 1D).

\section{Pathogen sharing between native and exotic plants correlates with exotic plant impact}

When comparing the change in proportional plant biomass from what was originally planted to what was realized in plant communities, native plants were $40 \%$ lower in proportional biomass at the end of the experiment than at initial planting, whereas exotic plants were $60 \%$ larger, on average. Native plant performance 
(relative interaction intensity index, RII) decreased as the proportion of pathogens shared between native and exotic plants increased $\left(\chi^{2}=5.72, \mathrm{p}<0.02\right.$, Fig. $\left.4 \mathrm{~A}\right)$. In fact, the proportional native plant biomass from the beginning to the end of the experiment was consistently reduced in every community where exotic plants shared $30 \%$ or more of their pathogens with them (Fig. 4A). In contrast, the correlation between pathogen sharing and exotic plant success was not significant (Fig. 4B); rather, exotic plants made up a greater proportion of community biomass compared to that which they were planted in nearly every community where they grew.

Plant-soil feedbacks in monoculture do not predict feedbacks in a community

Native and exotic plants showed opposite responses to plant-soil feedbacks, when grown in monoculture. Exotics showed strong negative feedback when grown in their home soils, whereas natives benefitted from their home soil $\left(\chi^{2}=48.81, \mathrm{p}<0.001\right.$, Fig. 5A). Exotic plants grown in away soil were over $20 \%$ larger than exotics grown in home soil, whereas native plants grown in away soil were $12 \%$ smaller than natives grown in home soil.

However, the apparent benefit of plant-soil feedbacks to natives in monoculture were not apparent when plants were grown in communities. In communities, exotic plants were approximately 9 times larger than native plants $\left(\chi^{2}=20.07, \mathrm{p}<0.001\right.$, Fig. 5B). As reported in Waller et al. (2020), total plant community biomass across mesocosms was reduced in home soil, but these soil effects did not differ with provenance or the proportion of exotics planted in the community.

\section{DISCUSSION}

Our experiment revealed that soil pathogens accumulated more in exotic-dominated communities and, on average, those pathogens tended to be more generalist than those supported by plants in native-dominated communities. We observed a pattern of pathogen sharing congruent with asymmetric spillover, whereby native plants shared more pathogens with exotics than with other natives. Moreover, exotic plants showed strong potential to indirectly affect co-occurring native plants by spreading pathogens, whereas native plants had less influence over shared pathogen interactions. This asymmetric influence and sharing of generalist soilborne pathogens from exotic to native plants correlated with impacts of exotics on native plants, suggesting that pathogen sharing had disproportionate impacts on native plant performance. These findings suggest that generalist fungal pathogens may constitute a feedback that increases exotic plant dominance in mixed communities of native and exotic plants.

Host richness and diversity can strongly influence disease dynamics (Susi et al. 2020), but our results suggest a stronger role of species identity, and more specifically, of provenance. Pathogen transmission is predicted to be lower in diverse communities (Mitchellet al. 2002), where pathogen abundance decreases via the dilution effect when suitable hosts occur at low abundance (Ostfeld \& Keesing 2000). However, there is also evidence to suggest that more diverse plant communities can have higher pathogen densities as a result of amplification of generalists (i.e. pathogens that don't respond to host density) (Power \& Mitchell 2004; Halliday et al . 2017), particularly in plant communities containing fast-growing, less defended species (Cappelli et al. 2020). Our communities were all planted with the same initial plant richness, but native plants amplified more specialist pathogens in communities where they grew exclusively, whereas exotic plants amplified more generalists wherever they occurred. This difference appeared to have consequences for plant richness in communities, as plant richness was largely maintained to the end of the experiment in native communities, but declined sharply in exotic-dominated communities (reported in Waller et al. 2020). Our results suggest that declines in richness in exotic-dominated communities were due to increases in abundance of generalist pathogens that were amplified by exotic hosts, leading to apparent competition driving native biomass declines or mortality.

This study underscores the importance of conducting simultaneous plant-soil feedback experiments on plants grown alone and in communities, paired with characterization of the microbial communities. When grown in the monoculture feedback experiment, exotic plants were suppressed by soil previously inhabited by themselves, but this soil-mediated inhibition disappeared when these plants were grown in communities where 
they shared root pathogens. Viewed in isolation, and without the fungal community analysis, results from the monoculture experiment would suggest that specialist soil biota confers biotic resistance against exotic plants. However, when viewed in a community context, it appears more likely that sharing of generalist pathogens contributes to the competitive exclusion of natives by exotics, as a higher degree of pathogen sharing between exotic and native plants correlated with exotic impact in mixed communities. These results support a previous modeling study showing that exotic plants that accumulate generalist pathogens can spread and displace native plants, conditional on native fitness being more strongly affected by pathogens than the exotics (Eppinga 2006). More broadly, the divergent findings between the monoculture and community-level experiments may help explain why greenhouse plant-soil feedback experiments do not always translate into what is observed in the field (Heinze et al. 2016; Foreroet al. 2019).

Our findings indicate that exotic plants are amplifying and spreading generalist pathogens that are present in communities, resulting in reduced native plant success. We cannot determine whether the pathogen sharing between native and exotic plants constituted co-introduced non-native pathogens ("spillover", e.g. Bufford et al. 2016) or native pathogens ("spillback", e.g. Levine et al. 2004; Boreret al. 2007), as we do not know the provenance of the pathogens in this study. Either scenario can increase exotic plant success (Power \& Mitchell 2004; Dickie et al. 2017), though spillback may be more common in plant invasions (Strauss et al. 2012). Indeed, many introduced plants experience a short-term release from pathogens in their newly introduced range (Mitchell \& Power 2003), but begin to accumulate pathogens in their new range anywhere from 50-200 years after introduction (Hawkes 2007; Diez et al. 2010; Sikes et al. 2018). However, a high proportion of global pathogens are non-native to the area where they are recorded (Pimental 2001; Rua et al. 2011), so it would not be unreasonable to assume that many of the pathogens from our experiment were non-native.

Exotic plant invasions threaten biodiversity and ecosystem functions worldwide (Mack et al. 2000). Understanding how some invaders come to dominate native systems is therefore crucial to mitigating their impacts. Our results indicate that exotic plants benefit from fungal pathogen accumulation via disproportionate pathogen sharing with native plants.

\section{ACKNOWLEDGEMENTS}

We are very thankful for the help from Jim Allen, Neroli Allen, Barbara Barratt, Jennifer Bufford, Larry Burrows, David Conder, Leo Condron, Daniel Dash, Lochlan Dickie, Karen Dohrman, Filipe França, Beccy Ganley, Travis Glare, Andrew Holyoake, John Hunt, David Jack, Chris Johns, Eirian Jones, Jo Johns, Nina Koele, Craig Kunitsky, Brian Kwan, Stuart Larsen, Hamish Lea, Ian Luxford, Francesco Martoni, Rebecca McDougall, Aimee McKinnon, Gerry McSweeny, Leona Meachen, Maureen O'Callaghan, Kate Orwin, Alexandra Puértolas, Brent Richards, Hayley Ridgway, Ralph Scott, Marcus-Rongowhitiao Shadbolt, Georgia Steel, Ralph Wainer, Dean Waller, Mark Waller, Steve Wakelin, and Sandy Wilson. This project was supported by Centre of Research Excellence funding to the Bio-Protection Research Centre from the Tertiary Education Commission of New Zealand. JDT is supported by a Rutherford Discovery Fellowship administered by the Royal Society Te Apārangi (RDF-18-UOC-007).

\section{REFERENCES}

Allen W. J., Waller L. P., Barratt B. I. P., Dickie I. A., Tylianakis J. M. (2021). Exotic plants accumulate and share herbivores yet dominate communities via rapid growth. Nature Comm ., in press (accepted).

Allen, W. J. (2020). Indirect biotic interactions between non-native plants and native plants and animals. In: Traveset A, Richardson DM (eds.), Plant Invasions: The Role of Species Interactions. CABI Publishing.

Armas, C., Ordiales, R. \& Pugnaire, F. I. (2004). Measuring plant interactions: A new comparative index. Ecology , 85, 2682-2686.

Ashton, I. W. \& Lerdau, M. T. (2008). Tolerance to herbivory, and not resistance, may explain differential success of invasive, naturalized, and native North American temperate vines. Divers. Distrib., 14, 169-178. 
Bates, D., Mächler, M., Bolker, B. \& Walker, S. (2014). Fitting linear mixed-effects

models using lme4. arXiv preprint arXiv:1406.5823.

Bever, J. D., Westover, K. M. \& Antonovics, J. (1997). Incorporating the soil

community into plant population dynamics: the utility of the feedback approach. J. Ecol., 561-573.

Bever, J. D., Mangan, S. A. \& Alexander, H. M. (2015). Maintenance of Plant Species

Diversity by Pathogens. Annu. Rev. Ecol. Evol. Syst., 46, 305-325.

Borer, E. T., Hosseini, P. R., Seabloom, E. W., \& Dobson, A. P. (2007). Pathogen-

induced reversal of native dominance in a grassland community. P. Nat. Acad. Sci. USA, 104, 5473-5478.

Brinkman, P. E., van der Putten, W. H., Bakker, E. J., \& Verhoeven, K. J. (2010). Plant-soil feedback: experimental approaches, statistical analyses and ecological interpretations. J. Ecol., 98 , 1063-1073.

Bufford, J. L., Hulme, P. E., Sikes, B. A., Cooper, J. A., Johnston, P. R. \& Duncan, R. P. (2016). Taxonomic similarity, more than contact opportunity, explains novel plant-pathogen associations between native and alien taxa. New Phytol. , 212, 657-667.

Burdon, J. J., \& Chilvers, G. A. (1982). Host density as a factor in plant disease

ecology. Annu. Rev. Phytopathol., 20, 143-166.

Cappelli S. L., Pichon, N. A., Kempel, A. \& Allan, E. (2020). Sick plants in grassland

communities: a growth-defense trade-off is the main driver of fungal pathogen abundance. Ecol. Lett., 23, 1349-1359.

Cronin, J. P., Welsh, M. E., Dekkers, M. G., Abercrombie, S. T., \& Mitchell, C. E. (2010).

Host physiological phenotype explains pathogen reservoir potential.Ecol. Lett., 13, 1221-1232.

Delgado-Baquerizo, M., Guerra, C. A., Cano-Díaz, C., Egidi, E., Wang, J. T., Eisenhauer,

N., Singh, B. K. \& Maestre, F. T. (2020). The proportion of soil-borne pathogens increases with warming at the global scale. Nat. Clim. Change, 1-5.

Dickie, I. A., Bufford, J. L., Cobb, R. C., Desprez-Loustau, M. L., Grelet, G., Hulme, P. E.,

Klironomos, J., Makiola, A., Nunez, M. A., Pringle, A. and Thrall, P. H. Tourtellot, S. G., Waller, L. P. \& Williams, N. M. (2017). The emerging science of linked plant-fungal invasions. New Phytol., 215, 1314-1332.

Diez, J. M., Dickie, I., Edwards, G., Hulme, P. E., Sullivan, J. J., \& Duncan, R. P. (2010).

Negative soil feedbacks accumulate over time for non-native plant species. Ecol. Lett., 13, 803-809.

Dinoor, A. \& Eshed, N. (1984). The role and importance of pathogens in natural

plant communities. Annu. Rev. Phytopathol. , 22, 443-466.

Dormann C. F. (2011). How to be a specialist? Quantifying specialisation in

pollination networks. Network Biology, 1, 1-20.

Eppinga, M. B., Rietkerk, M., Dekker, S. C., De Ruiter, P. C. \& Van der Putten, W. H.

(2006). Accumulation of local pathogens: a new hypothesis to explain exotic plant invasions. Oikos 114, 168-176.

Forero LE, Grenzer J, Heinze J, Schittko C, Kulmatiski A. (2019). Greenhouse- and

field-measured plant-soil feedbacks are not correlated. Front. Env. Sci ., 7, 184. 
Fox, J. \& Weisberg, S. (2019). An R Companion to Applied Regression, Third edition. Sage, Thousand Oaks CA.

Frostegard, A., Tunlid, A. \& Baath, E. (2011). Use and misuse of PLFA measurements in soils. Soil Biol. Biochem . 43, 1621-1625.

Gianoli, E. \& Salgado-Luarte, C. (2017). Tolerance to herbivory and the resource availability hypothesis. Biol. Lett., 13, 20170120.

Gilbert, G. S. (2002). Evolutionary ecology of plant diseases in natural ecosystems.

Annu. Rev. Phytopathol. , 40, 13-43.

Goss, E. M., Kendig, A. E., Adhikari, A., Lane, B., Kortessis, N., Holt, R. D., Clay, K.,

Harmon, P. F. \& Flory, S. L. (2020). Disease in Invasive Plant Populations. Annu. Rev. Phytopathol, 58, 15.1-15.21.

Halliday, F. W., Heckman, R. W., Wilfahrt, P. A. \& Mitchell, C. E. (2017). A multivariate test of disease risk reveals conditions leading to disease amplification. Proc. R. Soc. B: Biol. Sci., 284, 20171340.

Hawkes, C. V. (2007). Are Invaders Moving Targets? The Generality and Persistence of Advantages in Size, Reproduction, and Enemy Release in Invasive Plant Species with Time since Introduction. Am. Nat., 170, 832-843.

Hawksworth, D. L. (2001). The magnitude of fungal diversity: the 1.5 million species estimate revisited. Mycol. Res., 105, 1422-1432.

Heinze, J., Sitte, M., Schindhelm, A., Wright, J. \& Joshi, J. (2016). Plant-soil feedbacks:

a comparative study on the relative importance of soil feedbacks in the greenhouse versus the field. Oecologia $181,559-569$.

Holt, R. D. (1977). Predation, apparent competition, and the structure of prey

communities. Theor. Popul. Biol. 12, 197-229.

Holt, R. D. \& Bonsall, M. B. (2017). Apparent Competition. Annu. Rev. Ecol. Evol. Syst., 48, 447-471.

Ihrmark, K., Bodeker, I., Cruz-Martinez, K., Friberg, H., Kubartova, A., Schenck, J.,

Strid, Y., Stenlid, J., Brandstrom-Durling, M., Clemmensen, K. E. \& Lindahl, B. D. (2012). New primers to amplify the fungal ITS2 region-evaluation by 454 -sequencing of artificial and natural communities. FEMS Microbial. Ecol., 82, 666-677.

Keane, R. M. \& Crawley, M. J. (2002). Exotic plant invasions and the enemy release hypothesis. Trends Ecol. Evol. , 17, 164-170.

Keesing, F., Holt, R. D. \& Ostfeld, R. S. (2006). Effects of species diversity on disease risk. Ecol. Lett. , 9, 485-498.

van Kleunen, M., Weber, E. \& Fischer, M. (2010). A meta-analysis of trait

differences between invasive and non-invasive plant species. Ecol. Lett., 13, 235-245. 
Klironomos, J. N. (2003). Variation in plant response to native and exotic arbuscular mycorrhizal fungi. Ecology , 84, 2292-2301.

Leishman, M. R., Haslehurst, T., Ares, A. \& Baruch, Z. (2007). Leaf trait relationships of native and invasive plants: community- and global-scale comparisons.New Phytol., 176, 635-643.

Lenth, R. (2020). emmeans: Estimated Marginal Means, aka Least-Squares Means. R package version 1.5.0. https://CRAN.R-project.org/package=emmeans

Levine, J. M., Adler, P. B. \& Yelenik, S. G. (2004). A meta-analysis of biotic resistance to exotic plant invasions. Ecol. Lett. , 7, 975-989.

Mack, R. N., Simberloff, D., Lonsdale, M. W., Evans, H., Clout, M. \& Bazzaz, F. A.

(2000). Biotic invasions: causes, epidemiology, global consequences, and control. Ecol. Appl., 10, 689-710.

Malmstrom, C. M., McCullough, A. J., Johnson, H. A., Newton, L. A., \& Borer, E. T. (2005). Invasive annual grasses indirectly increase virus incidence in California native perennial bunchgrasses. Oecologia, 145, 153-164.

Mitchell, C. E., Tilman, D. \& Groth, J. V. (2002). Effects of grassland plant species diversity, abundance, and composition on foliar fungal disease. Ecology , 83, 1713-1726.

Mitchell, C. E. \& Power, A. G. (2003). Release of invasive plants from fungal and viral pathogens. Nature, $421,625-627$.

Mitchell, C. E., Blumenthal, D., Jarošík, V., Puckett, E. E., \& Pyšek, P. (2010). Controls on pathogen species richness in plants' introduced and native ranges: roles of residence time, range size and host traits.Ecol. Lett. , 13, 1525-1535.

Mordecai, E. A. (2011). Pathogen impacts on plant communities: unifying theory, concepts, and empirical work. Ecol. Monogr. , 81, 429-441.

Nguyen, N. H., Song, Z., Bates, S. T., Branco, S., Tedersoo, L., Menke, J., Schilling, J. S. \& Kennedy, P. G. (2016). FUNGuild: an open annotation tool for parsing fungal community datasets by ecological guild. Fungal Ecol. , 20, 241-248.

Ostfeld, R. S. \& Keesing, F. (2000). Biodiversity series: the function of biodiversity in the ecology of vector-borne zoonotic diseases. Can. J. Zool., 78, 2061-2078.

Parker, I. M. \& Gilbert, G. S. (2004). The Evolutionary Ecology of Novel Plant-Pathogen Interactions. Annu Rev. Ecol. Evol. S., 35, 675-700.

Parker, I. M. \& Gilbert, G. S. (2007). When there is no escape: the effects of natural enemies on native, invasive, and non-native plants.Ecology , 88, 1210-1224.

Paull, S. H., Song, S., McClure, K. M., Sackett, L. C., Kilpatrick, A. M. \& Johnson, P. T.

(2012). From superspreaders to disease hotspots: linking transmission across hosts and space. Front. Ecol. Envir., 10, 75-82.

Pimentel, D., McNair, S., Janecka, J., Wightman, J., Simmonds, C., O’Connell, C., Wong,

E., Russel, L., Zern, J., Aquino, T. et al. (2001). Economic and environmental threats of alien plant, animal, and microbe invasions. Agric. Ecosyst. Environ., 84, 1-20.

Power, A. G. \& Mitchell, C. E. (2004). Pathogen spillover in disease epidemics. the

Am. Nat. , 164, S79-S89. 
Rognes, T., Flouri, T., Nichols, B., Quince, C. \& Mahé, F. (2016). VSEARCH: a versatile open source tool for metagenomics. PeerJ , 4, e2584.

Rúa, M. A., Pollina, E. C., Power, A. G., Mitchell, C. E. (2011). The role of viruses in biological invasions: friend or foe? Curr. Opin.Virol ., 1, 68-72.

R Core Team (2019). R: A language and environment for statistical computing. R Foundation for Statistical Computing, Vienna, Austria. URL https://www.R-project.org/.

Roy, B. A. \& Kirchner, J. W. (2000). Evolutionary dynamics of pathogen resistance and tolerance. Evolution, 54, 51-63.

Sikes B. A., Bufford J. L., Hulme P. E., et al. (2018). Import volumes and biosecurity interventions shape the arrival rate of fungal pathogens. PLoS Biol., 16, e2006025.

Strauss, S. Y. \& Agrawal, A. A. (1999). The ecology and evolution of plant tolerance to herbivory. Trends Ecol. Evol., 14, 179-185.

Strauss, A., White, A., \& Boots, M. (2012). Invading with biological weapons: the importance of disease-mediated invasions. Func. Ecol., 26, 1249-1261.

Stricker, K. B., Harmon, P. F., Goss, E. M., Clay, K., \& Luke Flory, S. (2016). Emergence and accumulation of novel pathogens suppress an invasive species.Ecol. Lett., 19, 469-477.

Susi, H., \& Laine, A. L. (2020). Agricultural land use disrupts biodiversity mediation of virus infections in wild plant populations. New Phyt.

Tylianakis, J. M., Martinez-Garcia, L. B., Richardson, S. J., Peltzer, D. A., \& Dickie, I. A.

(2018). Symmetric assembly and disassembly processes in an ecological network. Ecol. Lett., 21, 896-904.

Waller, L. P., Allen, W. J., Barratt, B. I. P., Condron, L. M., Franca, F. M., Hunt, J. E.,

Koele, N., Orwin, K. H., Steel, G. S., Tylianakis, J. M. \& Wakelin, S. A. (2020). Biotic interactions drive ecosystem responses to exotic plant invaders. Science, 368, 967-972.

\begin{tabular}{lllllll}
\hline $\begin{array}{l}\text { Response } \\
\text { variable }\end{array}$ & $\begin{array}{l}\text { Community- } \\
\text { level }\end{array}$ & $\chi^{2}$ & $P$ & $\begin{array}{l}\text { Individual- } \\
\text { level }\end{array}$ & $\chi^{2}$ & $P$ \\
\hline $\begin{array}{l}\text { a. Pathogen } \\
\text { richness }\end{array}$ & Exotic & 1.05 & 0.30 & Provenance & 1.310 .25 & 1.310 .25 \\
& & & & & \\
& Soil & 2.67 & 0.10 & Soil & 2.26 & 0.11 \\
& Exot. x Soil & 1.89 & 0.17 & Prov. x Soil & 1.28 & 0.26 \\
$\begin{array}{l}\text { b. Pathogen } \\
\text { relative }\end{array}$ & Exotic & 5.17 & $\mathbf{0 . 0 2}$ & Provenance & 1.31 & 0.25 \\
$\begin{array}{l}\text { abundance } \\
\text { Soil }\end{array}$ & & & & & \\
& & 0.27 & 0.60 & Soil & 2.62 & 0.11 \\
$\begin{array}{l}\text { c. Plant } \\
\text { normalized } \\
\text { degree }\end{array}$ & Exot. x Soil & 3.31 & 0.07 & Prov. x Soil & 1.28 & 0.26 \\
& & 37.97 & $<\mathbf{0 . 0 0 1}$ & Provenance & 21.80 & $<\mathbf{0 . 0 0 1}$ \\
& Soil & & & & & 0.19 \\
\end{tabular}




\begin{tabular}{|c|c|c|c|c|c|c|}
\hline $\begin{array}{l}\text { Response } \\
\text { variable }\end{array}$ & $\begin{array}{l}\text { Community- } \\
\text { level }\end{array}$ & $\chi^{2}$ & $P$ & $\begin{array}{l}\text { Individual- } \\
\text { level }\end{array}$ & $\chi^{2}$ & $P$ \\
\hline & Exot. x Soil & 0.04 & 0.85 & Prov. x Soil & 1.82 & 0.18 \\
\hline \multirow{3}{*}{$\begin{array}{l}\text { d. Plant } \\
\text { weighted } \\
\text { centrality }\end{array}$} & Exotic & 15.68 & $<0.001$ & Provenance & 36.57 & $<0.001$ \\
\hline & Soil & 2.06 & 0.15 & Soil & 2.89 & 0.09 \\
\hline & Exot. x Soil & 1.86 & 0.17 & Prov. x Soil & 0.74 & 0.39 \\
\hline \multirow{3}{*}{$\begin{array}{l}\text { e. Pathogens } \\
\text { shared }\end{array}$} & Exotic & 6.37 & 0.01 & & & \\
\hline & Soil & 3.08 & 0.08 & & & \\
\hline & Exot. x Soil & 0.05 & 0.82 & & & \\
\hline \multirow{3}{*}{$\begin{array}{l}\text { f. Fungal } \\
\text { biomass } \\
\text { (PLFA) }\end{array}$} & Exotic & 0.16 & 0.69 & & & \\
\hline & Soil & 0.41 & 0.52 & & & \\
\hline & Exot. x Soil & 1.80 & 0.81 & & & \\
\hline \multirow{3}{*}{$\begin{array}{l}\text { g. Pathogen } \\
\text { normalized } \\
\text { degree }\end{array}$} & Exotic & 45.12 & $<0.001$ & & & \\
\hline & Soil & 0.36 & 0.55 & & & \\
\hline & Exot. x Soil & 0.04 & 0.83 & & & \\
\hline
\end{tabular}

Table 1. Structures and results of generalized linear mixed-effects models measured at the community and individual plant-level. Response variables a-g were tested as a function of the proportion of exotics planted in experimental communities, the soil treatment (home or away) and their interaction. Random factors were mesocosm (pot 1-80) nested in plant community (community 1-20). Response variables a-d were also tested as a function of plant provenance (native or exotic) and soil treatment. Random factors were the same as above plus plant species. All interactions were tested, but dropped from the models based on AIC. Significant factors $(\mathrm{p}<0.05)$ are designated in bold.

\section{Hosted file}

image1.emf available at https://authorea.com/users/412923/articles/521427-asymmetricpathogen-spillover-favors-exotic-plants-over-natives

Figure 1. Relationship between the proportion of exotic plants planted in the community and A. Relative abundance of sequences identified as plant pathogens in plant roots (pathogens sequences/total sequences). B. Normalized degree of plants (measures the generality of interactions by plants with pathogens), C. Normalized degree of pathogens (measures the generality of interactions by pathogens with plants) and D. Closeness centrality of plants (measure of the frequency in which plants share generalist pathogens with other plants). Closed circles represent native plants and open circles represent exotic plants in A, B \& D. Response variables were modelled on a $\log$ scale. All interactions were tested, but dropped from the models based on AIC.

\section{Hosted file}

image2.emf available at https://authorea.com/users/412923/articles/521427-asymmetricpathogen-spillover-favors-exotic-plants-over-natives

Figure 2. Estimated marginal means ( \pm s.e.) of (A) normalized degree and (B) closeness centrality values for plants (in their interactions with pathogens) growing in communities of only native plants (closed circles) and only exotic plants (open circles). 


\section{Hosted file}

image3.emf available at https://authorea.com/users/412923/articles/521427-asymmetricpathogen-spillover-favors-exotic-plants-over-natives

Figure 3. Relationship between exotic plant invasion and the proportion of putative fungal pathogens shared between native and exotic plants. A. Asymmetric sharing of pathogens between native and exotic plants in communities. The black line is fitted through the observed data from the community experiment showing the proportion of pathogens shared as a function of the realized proportion of exotics in pots, and the grey lines represent 1,000 simulations of a null model of random sharing. Note that proportions of 0 and 1 must have zero sharing by definition. B. Deviation between the observed (black line) and the null expectation (red line) of pathogen sharing between native and exotic plants. Together, A and B show that communities with few exotic plants have lower than random sharing of pathogens, whereas exotic-dominated communities have higher than random sharing.

\section{Hosted file}

image4.emf available at https://authorea.com/users/412923/articles/521427-asymmetricpathogen-spillover-favors-exotic-plants-over-natives

Figure 4. Relationship between the proportion of pathogens shared between native and exotic plants and the impact on realized biomass of $\mathrm{A}$. native and B. exotic plants in mixed communities. Impact on biomass is quantified using the relative interaction intensity index (RII), which measures the relative change in biomass from the beginning to the end of the experiment. Values above the grey line indicate plant growth that was greater than expected and below the line, lower than expected.

\section{Hosted file}

image5.emf available at https://authorea.com/users/412923/articles/521427-asymmetricpathogen-spillover-favors-exotic-plants-over-natives

Figure 5. Estimated marginal means ( \pm s.e.) of aboveground native and exotic plant biomass when grown in home or away soil in the A. monoculture plant-soil feedback experiment and B. community plant-soil feedback experiment. Different lowercase letters indicate significant differences $(p<0.05)$ between means. 